\title{
Cement with the addition of charred fermentation residues
}

\author{
Jiř́ Šál ${ }^{1, *}$ \\ ${ }^{1}$ The Institute of Technology and Businesses in Ceske Budejovice, Czech Republic
}

\begin{abstract}
This article focuses on the use and disposal of biochar waste from residual and waste biomass. Traditional use of this substance is its addition to arable land to improve its quality. The basic biochar component is a chemically stable carbon, which binds nutrients and other important substances to plant growth.

Positive effects on arable land have been sufficiently demonstrated, unfortunately amount of waste biochar is larger than what can be used in this way. That is why new opportunities need to be searched for. The area in which its use can be found is also building constructions. Recent research already underway focused on the addition of biochar to bricks and use as a plaster.

This paper explores further use of adding burnt fermentation residues to the cement composite. Cement is one of the most important materials in the construction industry, mainly used for concrete production. We live at a time when raw materials begin to vanish and need to be substituted, and at the same time that waste accumulates. That is why in the building constructions it is necessary to look for new ways. The use of hightemperature and fluid ash is already known to replace part of the cement. Using biochar may be another option.
\end{abstract}

\section{Introduction}

Nowadays, it is increasingly important to keep non-renewable raw materials. However, to preserve a certain standard of life, it is inconceivable to stop producing products or, in our case, to build only from renewable sources such as wood. Therefore, it is necessary to seek compensation for these raw materials. The best solution would be to replace all nonrenewable resources with renewable ones, but this is not always the case, so efforts must begin with replacing at least a certain amount.

Non-renewable sources of raw materials are deficient, on the contrary waste is surplus. Waste can be recycled to a certain extent. Some substances such as glass and iron can be recycled well. Plastics are already worse, but they are still looking for ways to reuse them. In any case, waste is sufficient and its use should be a priority.

There is also a need to look for new ways in the construction industry. This article deals with the concrete waste used as a cement admixture or the substitution of a part of cement for this substance. This is Biochar, the burned residue of waste biomass (figure 1).

\footnotetext{
*Corresponding author: sal@mail.vstecb.cz
} 
The use of high temperature and fluid ash is known to replace part of the cement. As an admixture for concrete, ash is commonly used in $15-20 \%$ by weight of cement. Within this range, qualitative factors are preserved, with good economic factors. It is proven that ash can improve some properties, such as the workability of fresh concrete, but positive properties can also have on hardened concrete. Ash is a traditional addition to concrete. [1], [2]

In a manner similar to the use of fly ash, biochar could also be used. This substance is already being used, for example, to improve the quality of arable land, since the basic component of biochar is a chemically stable carbon that binds nutrients and other important substances to plant growth. Efforts are also being sought for the use of this substance in the building industry, for example as a VOC-absorbing plaster [3] or as a lightweight brick. When replacing a portion of the cement by a biochar, it is expected to reduce the bulk density at the expense of the strength.

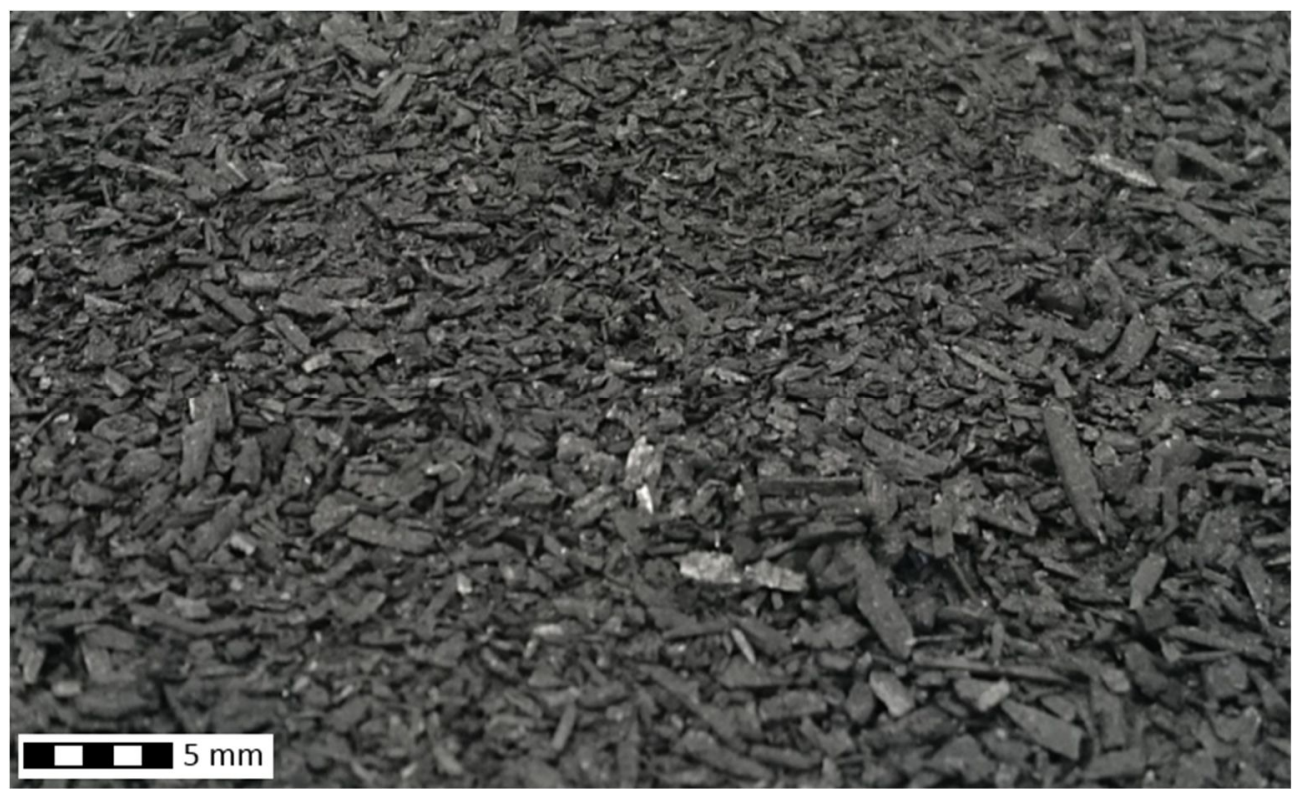

Fig 1. Biochar

\section{Formation sample}

The most important use of cement in the building industry is just as a binder in concrete. Replacing a portion of cement with a biochar directly in concrete specimens could affect the used aggregate. Therefore, for this research, only a mixture of cement, water and biochar was used. Thus, cement composites were examined, not concrete.

Mixtures for sample production were designed with a different percentage of biochar. The first set of samples did not contain a biochar, and served as a reference set. Additionally, sets were always 5\% higher than the previous ones. Thus, the sets were as follows: $0 \%, 5 \%, 10 \%, 15 \%$ and $20 \%$ of the total weight of the mixture. This means that cement has always been replaced by this percentage. It was also experimented with replacing $25 \%$ by weight of cement with a biochar. However, this mixture was very poorly processed and the water factor was too high, so the research was $20 \%$. Mixing characteristics for individual sample sets are shown in Table 1. 
Table 1. Characteristics of mixtures

\begin{tabular}{|c|c|c|c|c|c|c|}
\hline $\begin{array}{c}\text { Sample } \\
\text { set }\end{array}$ & $\begin{array}{c}\text { Volume of } \\
\text { cement [g] }\end{array}$ & $\begin{array}{c}\text { Volume of } \\
\text { Biochar [g] }\end{array}$ & $\begin{array}{c}\text { Volume of } \\
\text { Biochar [\%] }\end{array}$ & $\begin{array}{c}\text { Volume of } \\
\text { water [m] }\end{array}$ & $\begin{array}{c}\text { Volume of } \\
\text { drimix [g] }\end{array}$ & $\begin{array}{c}\text { Slump cone } \\
\text { test [mm] }\end{array}$ \\
\hline A & 1250,0 & 0 & 0 & 550 & 1250 & 160 \\
\hline B & 1187,5 & 62,5 & 5 & 550 & 1250 & 158 \\
\hline C & 1125,0 & 125,0 & 10 & 550 & 1250 & 157 \\
\hline D & 1062,5 & 187,5 & 15 & 600 & 1250 & 161 \\
\hline E & 1000,0 & 250,0 & 20 & 700 & 1250 & 162 \\
\hline
\end{tabular}

In order to achieve the smallest differences between the sample sets and the biochar content of the contents was sufficiently demonstrated, it was proposed to maintain the same water factor. Unfortunately, the biochar itself has a great absorption property, or water absorption, and therefore, at higher concentrations, more water was needed. Therefore, as a further constant, the infiltration in the cone spill test was used.

The samples were made according to ČSN EN 196-1, size 160x40x40 mm. (Figure 2)

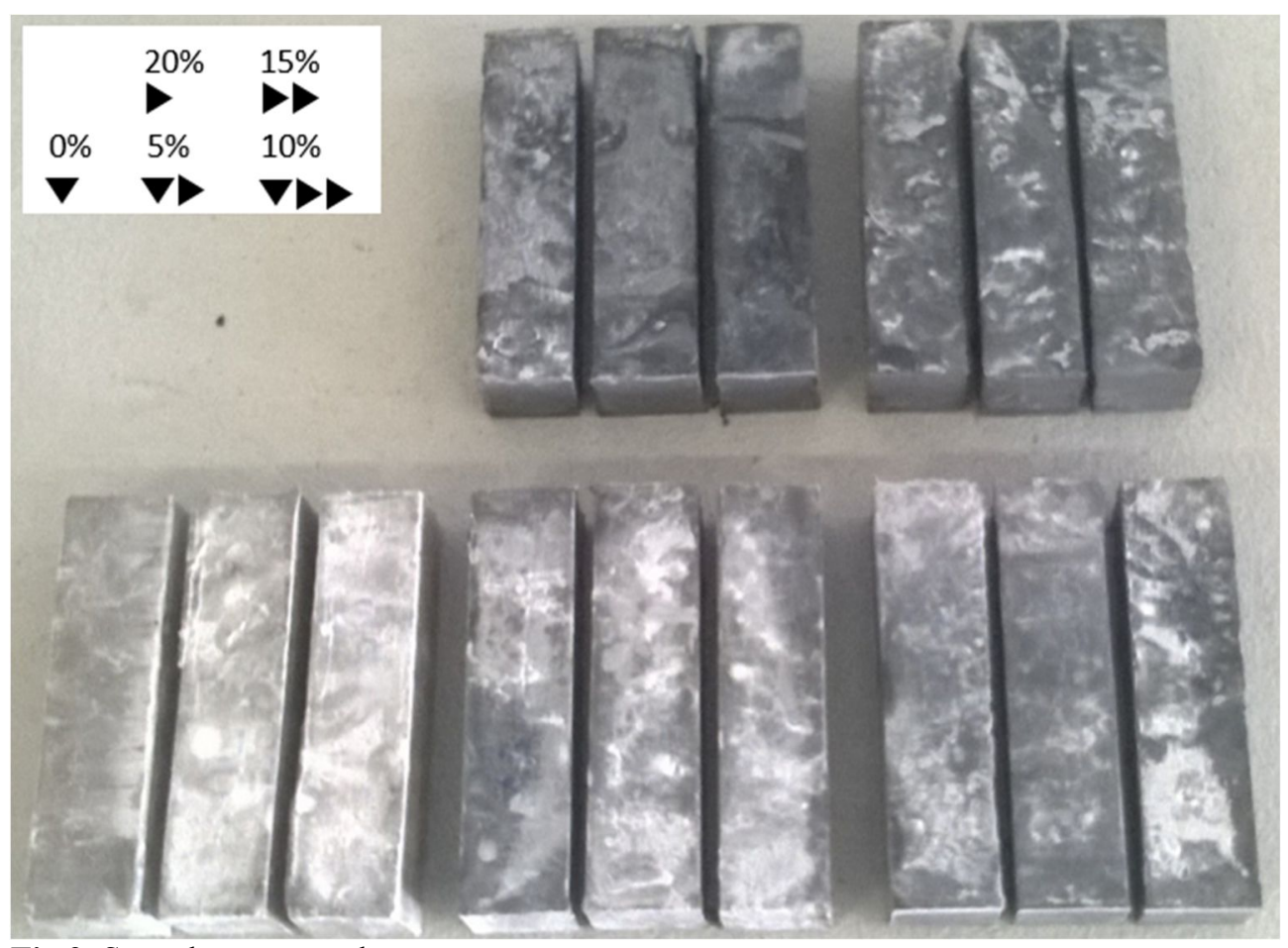

Fig 2. Some beams sample

\section{Subject $\&$ method of research}

The most important property that we are interested in concrete is the compressive strength, in the case of reinforced concrete, then the flexural strength. Both quantities were measured on cement beams, for the reasons described above. The results are shown in Figures 3 and 4. 


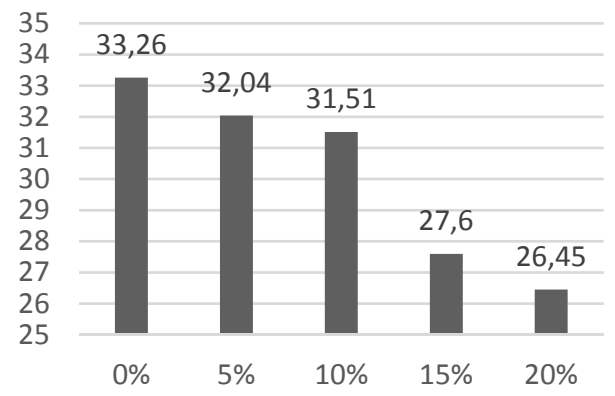

Fig 3. Compressive strength (MPa)

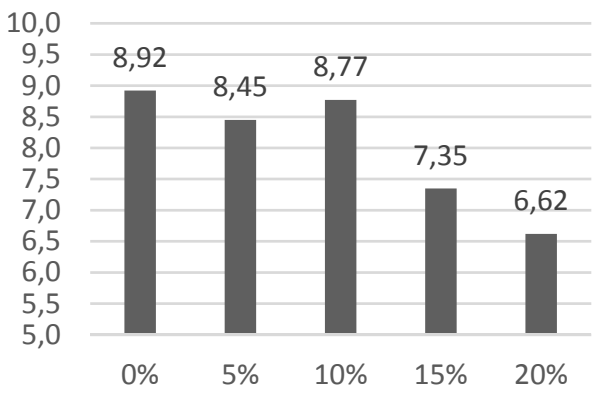

Fig 4. Flexural strength (MPa)

From the graphs (Figures 3 and 4) it is evident that the compressive and flexural strength decreased and the higher the biochar content. For samples up to $10 \%$ of the biochar, the strength decreased only slowly, followed by a sharp loss of strength. Interesting is the flexural strength increase of $10 \%$ biochar, compared to $5 \%$. This increase was additionally checked using additional sample control kits and verified as correct.

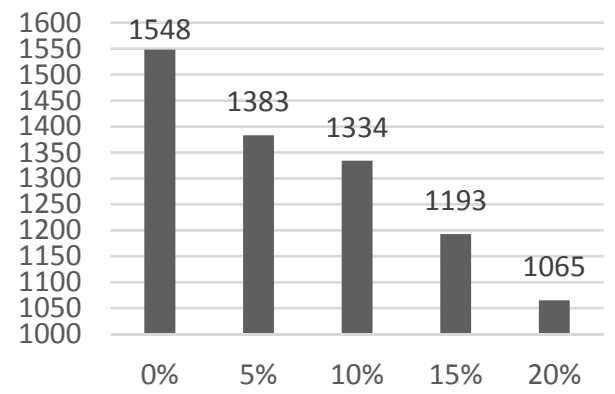

Fig 5. Volumetric mass density $(\mathrm{Kg} / \mathrm{m} 3)$

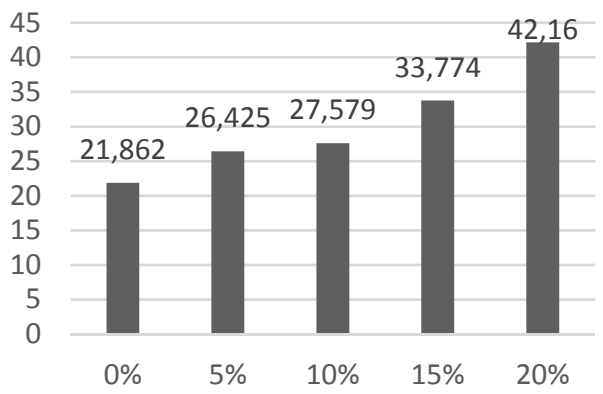

Fig 6. Water absorption (\%)

Another measured value is the volumetric mass density. Since the biochar has a large specific surface area [1], it is expected to replace the cement part by a biochar, reducing the volumetric mass density. This hypothesis was demonstrated by the measurement, the results of which are shown in Figure 5. When replacing the 5\% and 10\% percent, the decrease in volume by comparison with pure cement is clearly evident, but the difference between the two values is minimal. However, at $15 \%$ or more, the decrease is even greater.

Together with the decrease in volume, an increase in water absorption was expected. These results are shown in Figure 6. The increase in water absorption is directly proportional to the increase in the volume of the biochar, but there is no such difference in the values of $10 \%$ and $15 \%$ as in other measurements, where a clear jump is always visible.

\section{Results}

The measurement has demonstrated the hypothesis of reducing bulk density and reducing strength. With cements, we always have the strength of interest, and therefore it is important that the strength is reduced to a minimum. In our case, the compressive strength at $5 \%$ and $10 \%$ of the cement replacement by the biochar was reduced only minimally. The $5 \%$ impurity decreased the strength from $33.26 \mathrm{MPa}$ to $32.04 \mathrm{MPa}$ and $10 \%$ at $31.51 \mathrm{MPa}$. Even Flexural strength decreased. At 5\% it is from $8.92 \mathrm{MPa}$ to $8.45 \mathrm{MPa}$ and at $10 \%$ even at only $8.77 \mathrm{MPa}$. Which is very interesting when the strength at $10 \%$ does not drop as 
much as $5 \%$. If a larger amount of cement is replaced by a biochar, the strength value decreased and no more useable for carrier concrete.

Lower volumetric mass density indicates better thermal properties due to greater porosity. It is true that the larger the amount of cement we replace with the biochar, the lower the volumetric mass density. However, if we consider cement for concrete concretes, up to $10 \%$ of the biochar, according to the paragraph above, the volumetric mass density decreased from $1548 \mathrm{Kg} / \mathrm{m} 3$ to $1383 \mathrm{Kg} / \mathrm{m} 3$ and $1334 \mathrm{Kg} / \mathrm{m} 3$, respectively. This is a great reduction in volumetric mass density with only a small strength drop, as seen in Figure 7.

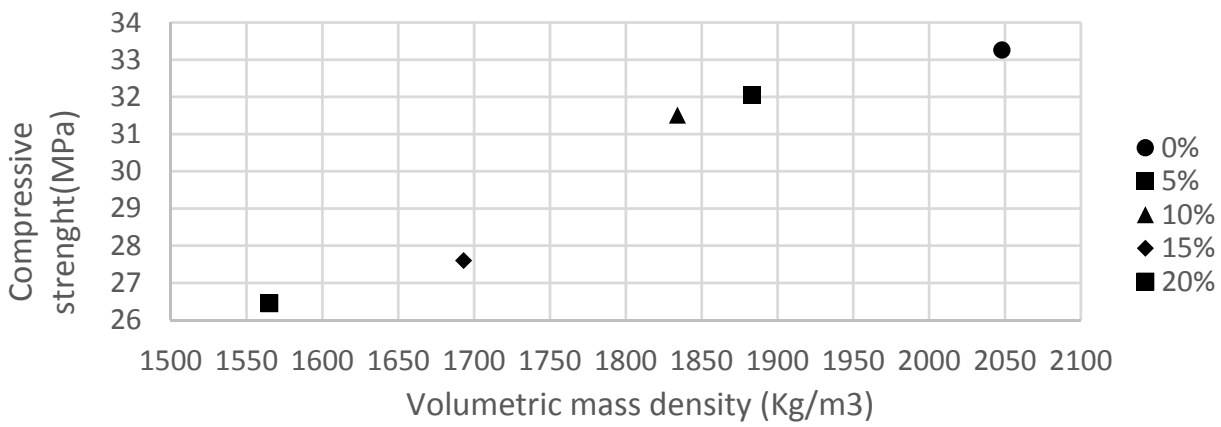

Fig 7. Graph of compressive strength versus volumetric mass density

\section{Conclusion}

In this paper, it has been proven that a part of cement can be replaced by a biochar for use in concrete. When replacing cement with $10 \%$ of this additive, cement can still be used in structural concrete. Above $10 \%$ substitution is still possible, but no structural concrete should be considered, but for example plastering. Over $25 \%$ of this substance is working poorly with cement slurry.

Biochar as a waste can be purchased without financial costs, so we can talk about financial savings, replacing, for example, $10 \%$ of the cement with a biochar. Then the resulting concrete is $10 \%$ cheaper. This can be a big savings especially for large producers.

We must not forget about the environmental waste disposal. Using biochars as waste is environmentally friendly.

Cement substitution by biochar was $5 \%$, so we do not have exact break data between use for structural and non-structural concrete. This fracture is between 10 and $15 \%$, for more accurate data, it would be necessary to create samples for example $1 \%$, that is to say, values of $11,12,13$ and $14 \%$. Then the quarry would definitely be determined.

\section{References}

1. F. Sybertz, Beurteilung der Wirksamkeit von Steinkohlen flugaschenals Betonzusatzstoff. Schriftenreihe des Deutschen Ausschusses für Stahlbeton, 434, BeuthVerlag, Berlin (1993)

2. P. Šiler, P. Bayer, T. Sehnal, I. Kolářová, T. Opravil, F. Šoukal, Construction and Building Materials, 78, 181-188, (2005)

3. V. Stehel, M. Vochozka, A. Maroušková, J. Šál, L. Kolář, Energy Sources, Part A: Recovery, Utilization and Environmental Effects, 301-305 (2017) 